\title{
Towards Making an Invisible Diversity Visible: A Study of Socially Structured Barriers for Purple Collar Employees in the Workplace
}

\author{
Zia Ullah 1,*(D), Esra AlDhaen ${ }^{2}\left(\mathbb{D}\right.$, Rana Tahir Naveed ${ }^{3}$, Naveed Ahmad ${ }^{4,5}{ }^{(D)}$, Miklas Scholz ${ }^{6,7,8,9, * \mathbb{D}}$, \\ Tasawar Abdul Hamid ${ }^{10}$ and Heesup Han ${ }^{11}$ (D)
}

\section{check for} updates

Citation: Ullah, Z.; AlDhaen, E.; Naveed, R.T.; Ahmad, N.; Scholz, M.; Hamid, T.A.; Han, H. Towards Making an Invisible Diversity Visible: A Study of Socially Structured Barriers for Purple Collar Employees in the Workplace. Sustainability 2021, 13, 9322. https://doi.org/10.3390/ su13169322

Academic Editors: Marc A. Rosen and Jim Arrowsmith

Received: 14 June 2021

Accepted: 16 August 2021

Published: 19 August 2021

Publisher's Note: MDPI stays neutral with regard to jurisdictional claims in published maps and institutional affiliations.

Copyright: (c) 2021 by the authors. Licensee MDPI, Basel, Switzerland This article is an open access article distributed under the terms and conditions of the Creative Commons Attribution (CC BY) license (https:// creativecommons.org/licenses/by/ $4.0 /)$.
1 Leads Business School, Lahore Leads University, Lahore 54000, Pakistan

2 Marketing Department, College of Business \& Finance, Ahlia University, Manama 10878, Bahrain; esaldhaen@ahlia.edu.bh

3 Department of Economics and Business Administration, Art \& Social Sciences Division, University of Education, Lahore 54770, Pakistan; tahir.naveed@ue.edu.pk

4 Faculty of Management Studies, University of Central Punjab, Lahore 54000, Pakistan; naveeddgk2010@gmail.com

5 Department of Management Sciences, Virtual University of Pakistan, Lahore 54000, Pakistan

6 Department of Building and Environmental Technology, Division of Water Resources Engineering, Faculty of Engineering, Lund University, P.O. Box 118, 22100 Lund, Sweden

7 Department of Civil Engineering Science, Kingsway Campus, School of Civil Engineering and the Built Environment, University of Johannesburg, P.O. Box 524, Aukland Park 2006, Johannesburg 2001, South Africa

8 Department of Town Planning, Engineering Networks and Systems, South Ural State University (National Research University), 76, Lenin Prospekt, 454080 Chelyabinsk, Russia

9 Institute of Environmental Engineering, Wroclaw University of Environmental and Life Sciences, ul. Norwida 25, 50-375 Wrocław, Poland

10 School of Commerce, Cardiff Metropolitan University, Cardiff CF5 2YB, UK; tasawar.abdulhamid@gmail.com

11 College of Hospitality and Tourism Management, Sejong University, Seoul 143-747, Korea; heesup.han@gmail.com

* Correspondence: chairperson.ba@leads.edu.pk (Z.U.); miklas.scholz@tvrl.lth.se (M.S.)

Abstract: Eunuchs and members of the transgender community are yet to be recognized as an effective human resource and this diversity in the workforce is still invisible. A tiny portion of the transgender community is employed, and they are tagged as purple collar employees. It is generally claimed that coworkers do not accept members of the transgender community in the workplace and are not willing to work with them due to their different personal, social, and work-related characteristics. This study aimed to investigate coworkers' attitudes towards transgender colleagues and their willingness to work with them in the workplace. We selected the Punjab province of Pakistan as the context for the study where more than five hundred thousand members of the transgender community live. We collected data from 363 randomly selected respondents working in an organization where transgender people also worked. We applied Structural Equation Modeling (SEM) to analyze the data. Our findings revealed that coworkers do not hesitate to work with transgender people merely based on their biological differences. Coworkers' willingness was more influenced by social attributes (trust and support) and work attributes (knowledge, ability, and motivation) irrespective of gender differences. The study strongly suggests tapping this invisible human resource and mainstreaming this resource to emancipate transgender people from poverty and to bring a productive diversity in the workforce. Government should frame policies to provide all human rights including national identity, health and educational facilities, and organizations should provide transgender people with jobs to properly utilize this untapped human resource.

Keywords: transgender; invisible diversity; workplace barriers; personal attributes; social attributes; work attributes 


\section{Introduction}

Different terms such as transvestites, intersexed individuals, female and male crossdressers, masculine females, feminine males, she male, transsexual, and third gender are used to denote transgender people [1,2]. Transgender people have unexpected configurations in particular parts of their bodies, such as the breast and penis or flat chests and the vagina, that produce a gender related dissonance. These biological and sex-related abnormalities can happen by birth or sometimes they are reassigned medically. Transgender people are known as Khawaja Sira and hijra in South Asian countries [3,4] particularly in the given context. It is a broad group that encompasses trans and intersex people, as well as eunuchs. In this context trans people consist only of those who possess predominantly male characteristics at birth and express themselves with a female gender identity. Thus, the terms transgender, eunuch, intersex, and transsexual commonly represent those who had dominant male characteristics at birth and express a female identity. In the same vein, the term transgender carries the same meaning in this study as it prevails in the context in hand.

The workplace is not welcoming for all kinds of employees. Typically, employees are discriminated in organizations on ethnic, religious, and socio-biological grounds $[5,6]$. Above all, discrimination experienced by transgender people starts with their very birth and continues throughout their lives, and no law, religion, culture, philanthropy, and human rights activities could bring them to the mainstream of human beings [7]. Since parents sometimes disown their transgender children, the childhood of transgender people is denied, and transgender people are deprived of education, health, and other basic amenities, and are excluded from economic and social circles, this equally important human resource is lost. When human resource managers talk about workforce diversity they mean male, female, disabled, and transgender people are ignored as a kind of human resource [8]. As a result of social exclusion and isolation, transgender people have formed their own community away from their families and social circles. These communities are managed and headed by their chiefs that are locally called gurus. Gurus provide them with the environment where they can lead their desirable lives which would otherwise become impossible. However, this isolation creates certain serious social issues such as the deprivation of education, health facilities, job opportunities, and social events. A very small stratum of the transgender community succeeds in obtaining jobs and they are titled purple collar workers [9-11]. In fact, despite increased legal protections and rights for lesbian, gay, and bisexual people, few laws specifically protect transgender people from discrimination, including employment and housing discrimination [12-14]. As a result, a fair majority of young trans women of color live in poverty, and experience high rates of unemployment, homelessness, and limited access to healthcare [15].

Surprisingly, despite physical, mental, and emotional soundness, transgender people are not accepted as equal to normal human being just because of certain biological incongruences, which do not apparently challenge their working capabilities. The problem arises when barriers are socially constructed to exclude transgender people from normal civic activities. Some exclusions produce glass ceiling effects, such as discrimination in the attainment of education, which causes a lack of employment and reduced choices in life. So, social exclusion reduces employment opportunities and most of the organizations do not have transgender people as their employees. The transgender community not only face impediments to employment, but even during employment they face abhorrence from coworkers and managers. Other employees hesitate to work with them, others exploit them, and some exclude them. So, one of the big job-related problems for transgender people is the attitude of other employees and coworkers at the workplace.

Employees demonstrate unfavorable behavior because of the personal and physical characteristics of transgender people [16]. Physical appearance is a dominant characteristic that influences social perception. Transgender people have distinct physical characteristics that are publicly disliked and are deemed socially undesirable. Transgender people usually suffer from an identity crisis. No language could present a pronoun to represent transgen- 
der people. So, employees feel embarrassed as they address them. Suitability for jobs is another question as transgender people are supposed to be for sex work and entertainment. They are not considered to be suitable for jobs other than dancing and sex work. The body language of transgender people is considered to be socially undesirable and perceived not to be commensurate with job requirements.

The social features of the transgender community do contribute to the formation of other employees' attitudes towards their transgender colleagues $[17,18]$. Employees usually put the least trust in transgender people, as they are suspicious of their honesty, reliability, and friendliness. Apart from a lack of trust in transgender people, coworkers become doubtful about having work support from transgender people. Coworkers think that transgender people may be weak in terms of being team members, sharing the workload, and being helpful and considerate. The work attributes of transgender people are also considered to be a misfit in a work setting. Transgender people are considered to be lacking in basic and crucial job-related characteristics including knowledge, abilities, and motivation.

This study attempts to highlight one of the most crucial resources that is still unrecognized in this resource-deficient world. A considerable portion of the human population consists of unspecific genders, generally titled as transgender people, who apparently have all the characteristics to perform any kind of job like a normal human being. It is not understood why this resource is still out of the mainstream of human capital. Many attributes such as job attitude, creativity, motivation, commitment, competence, and sense of responsibility in transgender people need to be explored and measured to encourage organizations to accept and own them as their employees. The present focus is on coworkers' willingness to work with their transgender counterparts. The study investigates how coworkers think of the personal, social, and work-related characteristics of transgender colleagues that in turn will determine their willingness to work with trans workers. So, the major purpose of the study is to identify whether coworkers create employment-related hurdles merely on the basis of the personal, social, and work-related characteristics of transgender people. We collected data from an organization that employs more than one thousand transgender people and it is situated in the city of Lahore, Punjab Pakistan.

\section{Literature Review}

Generally speaking, in the literature the term eunuch is specifically used for males who are castrated by chance or by choice and it refers to the men who lack reproductive capabilities [19]. On the other hand, male castration is very uncommon in the given context and the term eunuch is used to denote human beings with gender characteristics beyond male and female [20,21]. Although discrimination against gay men and lesbians has been documented with some consistency, research on the discrimination against transgender people has been less systematic; anecdotal data and self-reporting continue to be the main sources of information [22].

The term transgender is inclusive in nature and is used to define people whose gender identity is different from what is assigned as male or female [1]. Many sub-terms fall under the coverage of transgender such as intersexed individuals, female and male crossdressers, transvestites, masculine females, feminine males, or those who are sometimes called transsexuals when they obtain medical assistance to convert their gender [23]. They are also called male eunuchs, female eunuchs, and people of unisex gender [23,24]. Their gender identity, expression, and role do not match up with the sex they were assigned at birth. Though a very small amount of data exists related to transgender people and their encounters with violence, discrimination, and harassment, these maiden studies refer to a shocking trend [22]. The data has suggested that actions are necessary to guarantee workplace safety for transgender workers [25]. Even without proper and systematic data, a prima facie reflection on transgender communities suggests that violence, discrimination, and harassment do exist and that remedial measures would help them in the workplace. 
Discrimination occurs when governments, institutions, or individuals treat people differently on the basis of their personal attributes, such as (but not limited to) sex, gender identity, sexual orientation, ethnicity, age, race, or health status [26,27]. These kinds of discrimination can take several forms, including direct discrimination, indirect discrimination, and harassment. Lack of conformity to these social pressures translates into discrimination, harassment, and violence. Lombardi [28] offered the most comprehensive study of violence and discrimination against transgender people. The authors concluded that $59.5 \%$ of the sample had experienced violence or harassment in their lifetimes, and $37.1 \%$ had experienced economic discrimination. The authors also found a strong link between economic discrimination and violence, leading them to conclude that the workplace can be one of the most dangerous places for transgender people. The authors found that coworkers were the most likely perpetrators of sexual orientation or gender-based harassment.

In addition to general workplace violence, harassment, and discrimination, a few studies have explored schools as unique workplace environments. Kirk and Belovics [29] explored the workplace experiences of 120 gay men, lesbians, and transgender people employed as teachers, academics, and educators. He found that harassment was widespread in the educational environment. Sausa [30] interviewed transgender students, staff, and faculty about harassment and discrimination and found that schools were often ill-equipped to meet the needs of transgender people on campus - if not ignorant of their needs altogether. As a result, transgender people are often isolated or ignored.

Transgender discrimination in the formal labor market leads them to informal economic activities [31]. The majority of transgender people work in prostitution or begging due to the lack of opportunities within the formal economy. Problems start from their inadequate qualifications. It is common for them to leave formal education in their early years due to harassment and discrimination by school fellows [1]. If they are qualified and eligible they rarely receive responses from sent resumes [32,33]. When they get to the interview process, their names, appearance, and voice become an issue for the interviewer [34,35]. The level of prejudice and discrimination blocks the entry of transgender people during resume analyses or an interview [32].

Other colleagues only accept transgender people if their organization accepts and supports them through their rules and regulations regarding diversity [36,37]. Colleagues make it so difficult for transgender people to survive in an organization, from calling them names, intentionally confusing their pronouns he/she, cracking jokes about them, and pretending they are not even there [35]. Not letting them use the restrooms of their own choice and sometimes physical abuse can lead transgender people to resign [38].

Employees at work alienate themselves from transgender coworkers due to their personal characteristics [39]. Their personal attributes seem strange as these attributes do not align with either male or female attributes [40-42]. Employees maintain a distance as a result of the lack of the proper identity of transgender people and coworkers sometimes feel deficient in finding a suitable name or pronoun to address their transgender coworkers $[39,40]$. Some employees doubt the suitability of a transgender person for a job. Generally, transgender people are perceived to be entertainers and are considered misfits for any job otherwise. The body language of transgender people is also annoying to many coworkers [43]. The posture, body movement, voice pitch, and eye contact are not considered to be congruent with the job requirements.

The behavioral characteristics of transgender people do play a greater role in determining the perception of others $[44,45]$. The different behavioral structure of transgender people from that of males or females is usually unfamiliar to others and to work with a coworker with strange behavioral attributes may be uneasy [46]. That is why coworkers do not put their trust in transgender people and expect support from them as such [47]. The work attributes, such as knowledge, skill, abilities, and motivation of transgender people are also considered to be different from what is normally expected from employees at the workplace $[46,48]$. Since transgender people do not find education and training 
opportunities, they are supposed to be deficient in job-related characteristics including knowledge, skills, abilities, and motivation [49].

The literature states that transgender people face job-related problems and are underrepresented in workplaces. They are marginalized and even deprived of basic human rights including education, health, and other basic amenities. However, the literature does not provide the details of the causes of the socio-economic alienation of transgender people, particularly in the underdeveloped parts of the World. To the best of our knowledge, the literature does not contain studies explaining coworkers' attitudes towards transgender people regarding their personal, social, and work-related attributes and consequently their willingness to work with them. The study investigates employees' attitudes towards transgender people as their colleagues at the workplace; hence, we attempt to fill this gap in the related literature.

\section{Theoretical Framework}

Different theories including the reinforcement and stimulus-response theory, social judgment theory, consistency theory, functional theory, and the self-perception theory explain human attitude formation [50]. However, the Stereotype Content Model [51] provides a sound theoretical base for this study. This model states that people judge other people through two dimensions: warmth and competence. These judgments direct our behavior towards others. Warmth and competence are the universally accepted dimensions of social psychology that enable individuals to assess in-group peers and foreign groups or group members. These two dimensions determine the answer to the question "is he/she a friend or foe". The warmth dimension determines if we can put trust in someone. People are naturally obsessed with first assessing the other's intent to either help or harm them. If a person realizes that someone does not have a worthy intent towards him, he will go away. The second dimension, competence, is the judgment of the abilities of a person to translate his/her perceived good or bad intentions. In short, the Stereotype Content Model states that people judge and perceive the intents of a stranger and his ability to act on his intentions. The present study intends to explain whether coworkers accept transgender people as a part of their work environment and to what extent the coworkers are willing to work with them. So, we have supposed that coworkers judge the personal, social, and competence-related attributes of a transgender person at the workplace, and their judgment, in return, will determine their willingness to work with them.

\subsection{Variables and Their Definitions}

Generally speaking, the term transgender is a broad term used for all kinds of people who do not conform to either the male or female gender. A transgender person is a person whose gender identity differs from the sex the person had or was identified as having at birth; male, female, intersex, or a person whose gender identity is opposite the sex the person had or was identified as having at birth. However, in the present context, transgender, usually known as Kahwaja Sira or Hijra, refers to a person who was assigned a male gender at birth and expresses a female gender identity. They are only those who were male at birth with a female gender identity, and not vice versa. They even have apparent male features, such as a beard, a flat chest and have typical male voices but choose to identify as female.

The conceptual model of the study consists of four variables including the coworkers' willingness as an endogenous variable while personal attributes, social attributes, and work attributes are exogenous variables (as shown in Figure 1). The definitions of the variables are as follows:

The willingness of coworkers to work with transgender people is the criterion variable of the study. It defines whether the current employees were happy to work with transgender people as their colleagues in the same workplace. Do the coworkers feel comfortable while working with transgender people? We assumed that employees were willing to work with 
transgender people when they were comfortable discussing, eating, drinking, working or sharing the same room with them.

Personal Attribute describes the personality characteristics of a transgender person. These are the physical features including identity, apparent suitability for work, and the body language of a transgender person.

Social Attribute describes the behavioral characteristics of a eunuch. It is about trust and support. Trust shows the extent to which employees believe and have confidence in transgender people. Support shows the extent to which employees expected to receive help and cooperation from transgender colleagues.

Work Attributes describe the key characteristics that a transgender person should possess to perform an assigned task at the workplace. The key characteristics are pertinent knowledge, abilities, and motivation.

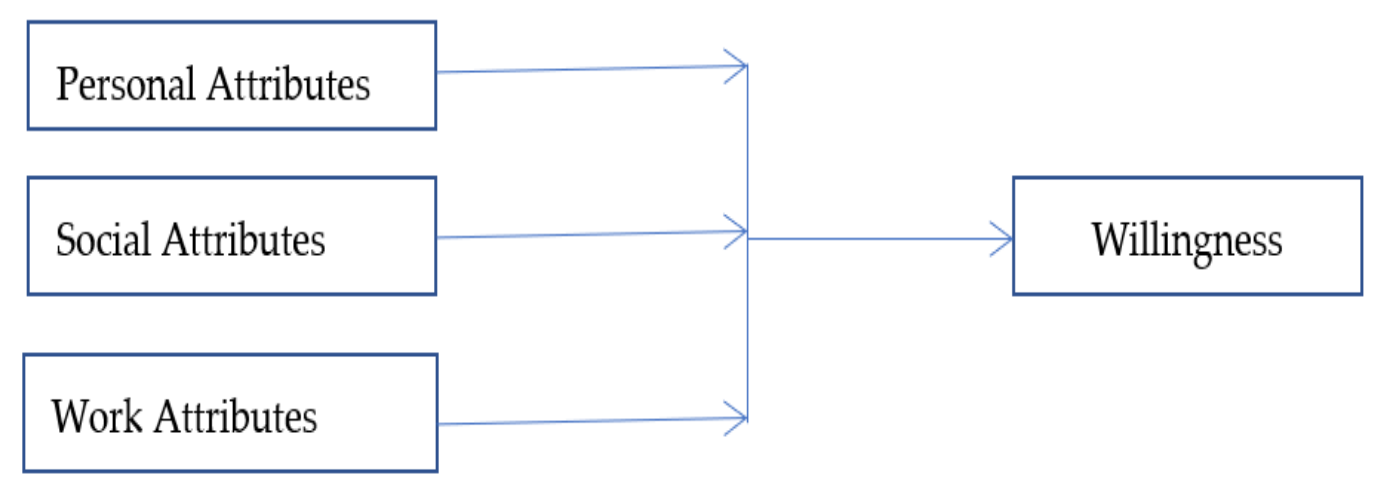

Figure 1. Research Model.

\subsection{Hypotheses}

Physical appearance attracts or distracts others [52]. Physical characteristics do play a profound role in impression management. Graceful identity, apparent suitability to a position in a hierarchy, and elegant body language are the magnetic characteristics that increase the willingness of others to interact with a person [53]. In the same vein, we assumed that transgender people usually suffer from identity crises and transgender people generally do not find proper titles and appellations to address them [54]. When the titles or names are socially or culturally undesirable, other people hesitate to interact with such people using these titles or names. The concept of the right person for the right job is always welcomed in the workplace. So, employees normally prefer to work with the employee who best matches with his/her position [55]. Lastly, body language does play a pivotal role in socialization. Body movements, gestures, and eye contact should be aligned with socially accepted manners otherwise distance is maintained with the person with deviant body language [56]. Since transgender people suffer from identity issues, they are assumed to be suitable for entertainment work only [3], and their body language is considered abnormal; as a result, their coworkers may not be willing to work with them $[2,32]$. Keeping in mind these facts we propose:

Hypothesis 1. Employees will be willing to work with transgender coworkers when the personal attributes of the transgender employees are socially desirable.

Social attributes are the behavioral characteristics of a person that other people consider prior to interacting with him/her [57]. The honesty, reliability, and friendliness of a person need to be observed in order to put trust in him/her. When one worker faces a trust deficit, he/she cannot develop and maintain a working relationship [58]. Another attribute among social attributes is the support extended to other employees. Employees prefer to work with a coworker who is a good team member, shares the workload, and is considerate and helpful [59]. As the transgender community lives in isolation, other 
people may not be properly aware of their honesty, reliability, and friendliness to put trust in them. Similarly, due to their work exposure, transgender people may not realize the importance of teamwork, workload sharing, and other workplace norms. Under such circumstances, employees may not be willing to work with their transgender coworkers. So, we hypothesized:

Hypothesis 2. Employees will be willing to work with transgender coworkers when the social attributes of the transgender employees contain socially desirable behaviors.

Job-related competence increases acceptability at the workplace [60]. Employees usually prefer to work with those who have sound job-related knowledge and skills, ability, and motivation [61]. Team members want to have competent people in their team, and they have a subordinate desire to have a competent boss. A superordinate wants competent subordinates and coworkers [62]. Transgender people usually do not find opportunities to obtain education and training, so the majority of them may lack job-related knowledge and skills. Transgender people believe that they are born to entertain people and they are not meant for some respectable jobs. So, they do not strive to prove this mindset wrong. Transgender people are usually discriminated and disgraced at the workplace and are considered to be inefficient, so they lose their motivation and even quit their jobs. Keeping in mind these facts, we assumed that transgender people were supposed to be deficient in job-related knowledge, abilities, and motivation and consequently coworkers may hesitate to work with them. Thus, we hypothesized that:

Hypothesis 3. Employees will be willing to work with transgender coworkers when the work attributes of the transgender employees have the job-related knowledge, ability, and motivation.

\section{Methods}

This study was quantitative, explanatory, and cross-sectional in nature. We applied the survey method to collect data. A large size NGO in the city of Lahore, Pakistan with more than five thousand employees, out of which one thousand employees were transgender, was chosen for data collection. This organization provides jobs to transgender people on a priority basis to bring them out of poverty and deprivation. Transgender people do their jobs in different departments with other employees, so this organization was the best place to collect data to test the proposed model.

Approval for data collection was obtained from the concerned authority and a written declaration was submitted to the human resource department of the organization to follow the code of ethics while collecting data. In addition to this, informed consent was obtained from the respondents for the provision of data voluntarily and willingly. The HR department cooperated in data collection and assigned the task of questionnaire administration and collection to an HR officer. The authors were asked not to visit the organization frequently during the COVID-19 pandemic. Necessary training was given to the HR officer on how to administer questionnaires and how to answer the expected queries of the respondents. Data were collected following the ethical guidelines presented in Helsinki Declaration. We also obtained approval from the ethical committee of Lahore Leads University Pakistan to ensure that no ethical issue was involved in the study as such.

\subsection{Sample and Demographics of Respondents}

The population of the study consisted of three departments of the organization where transgender people worked along with other workers. Four hundred and fifty employees were randomly selected from the list provided by the HR department. Our sampling method was similar to stratified random sampling. Departments with transgender people as their employees were segregated to a stratum and a sample was randomly drawn from the stratum to enhance the sample's representativeness. We received 389 questionnaires back and selected 363 questionnaires with an adequate level of accuracy for statistical analysis. The demographics of the respondents were: $52.50 \%$ respondents were male, and 
the remainder were females. By age group, $6 \%$ were younger than 21 years old, $46 \%$ were 22-35 years old, 21\% were 36-40 years old, 19\% were $41-50$ years old, and $8 \%$ were more than 50 years old. According to work experience, $38 \%$ had five or less than five years of experience, $42 \%$ had $6-12$ years experience, $13 \%$ had $13-16$ years experience, and $7 \%$ had more than 16 years of experience. According to rank, 19\% were managers and $81 \%$ were at non-managerial level positions. According to qualification, $21 \%$ had twelve years of education and $48 \%$ had bachelor's degrees.

Descriptive statistics explains the central tendency and variability of the data. Table 1 shows that the mean values (central tendency) of each variable were higher than 3.0 and slightly lower than 4.0. In the same way, the dispersion and variability (Standard Deviation) of the data was less than 1.0 for each variable.

Table 1. Descriptive Statistics.

\begin{tabular}{cccccc}
\hline & N & Minumum & Maximum & Mean & Std. Deviation \\
\hline Personal & 363 & 1 & 5 & 3.7583 & 0.07110 \\
Social & 363 & 1 & 5 & 3.8142 & 0.06721 \\
Work & 363 & 1 & 5 & 3.7996 & 0.06713 \\
Willingness & 363 & 1 & 5 & 3.8347 & 0.06301 \\
\hline
\end{tabular}

\subsection{Measurement Instrument}

A five-point Likert-type scale was used to measure the variables. Five items were used to measure the dependent variable (willingness), fourteen items were used to measure "Personal Attributes", eleven items were used to measure "Social Attributes", and ten items were used to measure "Work Attributes". As a result of factor analysis, we excluded 8 items of Personal Attributes, and 1 item of Work Attributes due to low outer loading. Reliability and validity tests were conducted to establish the consistency and accuracy of the instrument.

\subsection{Data Analysis}

We applied inferential statistics to the data to test our hypotheses. Prior to this, quality control tests including reliability and validity tests were carried out to assess the health of the data collected. A Partial Least Square (PLS) was used for Structural Equation Modeling (SEM). This method enables a researcher to investigate structural components (path model) and measurement components (factor model) in one model at the same time [63]. Therefore, structural equation modeling (SEM) gives an encompassing image of reliability, validity, and causality [64].

\section{Results}

5.1. Quality Control

5.1.1. Reliability

We tested for reliability using Cronbach's alpha and composite reliability tests (Table 2). Cronbach's alpha and composite reliability values higher than 0.70 indicate high internal consistency [65]. All the values of Cronbach's alpha and Composite Reliability were greater than the cutoff values, confirming the internal consistency (reliability) of the instrument.

Table 2. Construct Reliability and Validity.

\begin{tabular}{ccccc}
\hline & Cronbach's Alpha & Rho_A & $\begin{array}{c}\text { Composite } \\
\text { Reliability }\end{array}$ & $\begin{array}{c}\text { Average Variance } \\
\text { Extracted (AVE) }\end{array}$ \\
\hline Personal & 0.802 & 0.841 & 0.858 & 0.508 \\
Social & 0.919 & 0.926 & 0.932 & 0.556 \\
willingness & 0.822 & 0.865 & 0.878 & 0.600 \\
work & 0.930 & 0.934 & 0.941 & 0.641 \\
\hline
\end{tabular}




\subsubsection{Validity}

Keeping in view the occurrence of social desirability bias in the data, we carefully examined the questionnaire to avoid the possibility of leading, difficult, and ambiguous questions. We had informal discussions with transgender employees in the same organization on coworkers' attitudes and found similarities in the responses of transgender people and coworkers.

We measured convergent validity using AVE values (Table 2). When the Average Variance Extracted value of a construct is higher than 0.5 it is considered to be valid [66]. We tested for discriminant validity using the Fornell-Larcker Criterion and the HeterotraitMonotrait (HTMT) ratio. According to the Fornell-Larcker criterion, a latent variable should explain the variance of its own indicators better than the variance of other latent variables of a model [65]. So, as per the Fornell-Larcker criterion, discriminant validity was in place as each construct had a greater value than the correlation of other latent variables (Table 3). According to Heterotrait-Monotrait (HTMT) criterion, each construct should have a value less than 0.90 to establish discriminant validity [65]. So, this method also confirmed the discriminant validity of our instrument as all the values were less than the threshold value (Table 4).

Table 3. Discriminant Validity (Fornell-Larcker Criterion).

\begin{tabular}{ccccc}
\hline & Personal & Social & Willingness & Work \\
\hline Personal & 0.713 & & & \\
Social & 0.670 & 0.746 & & \\
willingness & 0.638 & 0.655 & 0.775 & 0.801 \\
work & 0.631 & 0.649 & 0.671 & \\
\hline
\end{tabular}

Table 4. Discriminant Validity (HTMT).

\begin{tabular}{cccc}
\hline & Personal & Social & Willingness \\
\hline Personal & & & \\
Social & 0.764 & & \\
willingness & 0.779 & 0.737 & 0.732 \\
work & 0.712 & 0.703 & \\
\hline
\end{tabular}

\subsubsection{Multicollinearity and Common Method Bias}

To check the possibility of multicollinearity and common method bias in the data we used a Variance Inflation Factor (VIF) analysis. When the values of VIF are below 0.5 the data will be multicollinearity-free, and if the values of VIF are below 3.3 there will be no risk of common method bias [67]. All the values of VIF were below 3.3, which thus ruled out the possibilities of both multicollinearity and common method bias (Table 5).

Table 5. Collinearity Statistics (VIF).

\begin{tabular}{cc}
\hline & Willingness \\
\hline Personal & 2.064 \\
Social & 2.149 \\
Work & 1.965 \\
\hline
\end{tabular}

\subsubsection{Correlation and Autocorrelation}

The correlation matrix indicates a positive association between variables. Since all the correlation coefficients fell between 0.63 and 0.67 , the relationships between variables were moderate (Table 6). As the variables were not highly correlated and all the values were below 0.80 , this indicates that there was not autocorrelation involved among variables. 
Table 6. Latent Variable Correlation.

\begin{tabular}{ccccc}
\hline & Personal & Social & Willingness & Work \\
\hline Personal & 1.000 & & & \\
Social & 0.670 & 1.000 & & \\
Willingness & 0.638 & 0.655 & 1.000 & \\
Work & 0.631 & 0.649 & 0.671 & 1.000 \\
\hline
\end{tabular}

\subsubsection{Structural Equation Modeling (Hypotheses Testing)}

The coefficient of determination or R Square shows that a 56\% change in the endogenous variable (willingness to work with transgender) was caused by the three exogenous variables (personal attributes, social attributes, and work attributes) included in the model (Table 7).

Table 7. Coefficient of Determination.

\begin{tabular}{ccc}
\hline & R Square & R Square Adjusted \\
\hline willingness & 0.561 & 0.557 \\
\hline
\end{tabular}

We included demographic variables including age, gender, experience, and position as control variables to check the possible contamination of the relationship. All the four demographic variables had no effect on the dependent variable as all the $p$ values remained insignificant (Table 8). So, demographic characteristics do not influence the willingness of employees to work with their transgender coworkers.

Table 8. Path Coefficients.

\begin{tabular}{cccccc}
\hline & $\begin{array}{c}\text { Original Sample } \\
(\mathbf{O})\end{array}$ & Sample Mean (M) & $\begin{array}{c}\text { Standard Deviation } \\
\text { (STDEV) }\end{array}$ & $\begin{array}{c}\text { T Statistics } \\
(\text { I O/STDEVI) }\end{array}$ & $p$ Values \\
\hline Age & 0.0131 & 0.0129 & 0.372 & 1.217 & 2.547 \\
Gender & 0.0153 & 0.0151 & 0.401 & 1.562 & 3.028 \\
Experince & 0.102 & 0.0998 & 0.053 & 1.860 & 0.638 \\
Position & 0.113 & 0.110 & 0.184 & 1.878 & 0.094 \\
Personal -> willingness & 0.238 & 0.233 & 0.071 & 4.023 & 0.001 \\
Social -> willingness & 0.270 & 0.279 & 0.067 & 5.153 & 0.000 \\
work -> willingness & 0.345 & 0.346 & 0.067 & 000 \\
\hline
\end{tabular}

For hypothesis testing, we performed Structural Equation Modeling (SEM) using SmartPLS (Table 8). All three hypotheses were substantiated. The first hypothesis, assuming the effect of personal characteristics of a transgender person on other employees' willingness to work with them, was proved: $\beta=0.238, p=0.001$, and $\mathrm{T}=3.372$. The Path coefficient (0.238) did not show a strong relationship; however, it established a moderate positive effect of the personal attributes of transgender people on coworkers' willingness to work with them. $p=0.001$ shows that the relationship was significant. T statistics (3.372) which were higher than the cutoff value (1.645) provide sufficient evidence against the null hypothesis and signified the outer model loading.

Our second hypothesis was accepted: $\beta=0.270, p=0.000$, and $t=4.023$. The Beta value (0.270) showed a moderate positive effect of social attributes of transgender people on coworkers' willingness to work with them. The $p$-value 0.000 determined the significance of the relationship while the $\mathrm{T}$ value (4.023) provided greater evidence against the null hypothesis and signified the outer model loading.

Our last hypothesis regarding the work attributes of transgender people was also accepted: $\beta=0.345, p=0.000$, and $t=5.153$. The Beta value (0.345) depicted a significant positive effect of work attributes of transgender people on other employees' willingness to work with them. The $p$-value 0.000 confirmed the significance of the relationship while the 
$\mathrm{T}$ value (4.023) gave sufficient evidence against the null hypothesis and signified the outer model loading.

\section{Discussion}

The data supported our hypothesis and some interesting things surfaced in this study. The most interesting finding was that workers did not hesitate to work with transgender people based only on their abnormal gender and sex structure. This finding is inconsistent with the existing literature to a great extent. A total of $86.5 \%$ of the respondents were willing to work with transgender people as colleagues and the remaining $13.5 \%$ were neutral on this question. However, none of the respondents expressed any abhorrence or dislike on the basis of gender differences. Our first hypothesis regarding the personal attributes of a transgender person yielded interesting results. The literature declared that the personal characteristics of transgender people are annoying for coworkers [68-71] but our findings revealed that the personal characteristics of transgender were not annoying for coworkers at the workplace. Although our data showed a relationship between the personal characteristics of a transgender person and a willingness to work, the relationship was not that strong $(\beta=0.238)$. According to our informal discussion with transgender people at the workplace, they were happy at the workplace and did not experience any kind of disgrace or insulting remarks from coworkers. Thus, we found that the personal characteristics of transgender person did not create any impediments for them regarding their jobs in Pakistan.

The second hypothesis was supported. The social attributes of workers (transgender) affected coworkers' willingness to work at the same place. Social attributes were found to be more impactful as compared to the personal attributes of an employee (transgender). The findings of the study are partly consistent with the literature as social attributes affect employees' willingness to work with a colleague (transgender) [72-75]. However, our findings exhibited that the social attributes of an employee have an impact on the attitude of coworkers irrespective of biological composition and gender. The findings are partly inconsistent with the literature as the social attributes of transgender people were not problematic for coworkers while the literature shows otherwise $[46,49,50]$. Social attributes including trust and support at work were necessary to work with others while employees did not feel any deficit of trust and lack of support from transgender people. According to the respondents, transgender people were equally trustworthy and were extended all possible support at work.

Our findings exhibited that work attributes were the most effective in determining the willingness of employees to work with other coworkers. Work attributes did affect coworkers' attitudes irrespective of the worker's gender configuration. The literature depicts that transgender people do not find a way forward to high-level education and training, and ultimately obtain white-collar jobs due to social isolation and certain glass ceilings $[76,77]$. According to our findings, coworkers did not observe any kind of work incompetence in transgender people. However, in this organization, transgender people were working in lower ranks such as packing clothes, counting, and ironing. This kind of work does not require high-level knowledge, skills, and abilities. As for as motivation is concerned, transgender people were found to be more motivated as they were performing their duties with more of a sense of responsibility as compared to other genders. Thus, it was confirmed that transgender people possessed the required competencies for lowerlevel or operational level jobs, but for higher or executive level jobs transgender people may lack the knowledge, skills, and motivation.

The study has certain methodological implications. Data were collected from an organization that aims to promote trans people as its employees. Employees know the value that the organization attaches to the trans employees. So, employees take care of trans employees too. Since the data were collected cross sectionally and from an organization where trans employees are protected, the findings may have compromised external validity. 


\section{Conclusions}

It is frequently reported in the literature that employees hesitate to have transgender people as their work partners. The abhorrence of coworkers towards trans employees has become a socially-engineered impediment to get and do a job for transgender. This gap is due to the gender non-conformity of trans people. Transgender people are considered to have socially deviant personal characteristics, a lack of appropriate job-related competence, and a lack of the social attributes necessary at the workplace. The study aimed to investigate the willingness of employees to work with transgender coworkers in the same workplace. This study is of great significance due to its context where a considerable population of transgender people exist and their representation in job market is negligible. We collected data from an organization in Lahore, Pakistan where transgender people were working with other male and female employees. A close ended questionnaire was administered to employees to assess their willingness to work with transgender people. The findings of the study confirmed that employee's personal characteristics, social attributes, and workrelated competence would determine the willingness of coworkers to share work with them. However, coworkers do not hesitate to work with transgender people just because of their different biological configuration or sexual composition. The personal characteristics of transgender people, including body language, do not irritate other colleagues and transgender people are considered to be trustworthy and supportive at the workplace. Transgender people do possess the required knowledge, abilities, and motivation for lowerlevel jobs; however, in our population we did not find transgender at higher-level jobs. Managers in the organization were satisfied with the performance of trans employees.

The demographics show that transgender people at an early age are not inclined towards jobs. Since transgender people are not usually educated and skilled, they cannot secure lucrative jobs. Thus, they prefer to remain in the world of begging and prostitution where they can earn more than from doing a job. When they grow beyond forty years of age, they lose their worth in the field of prostitution and entertainment. So, the majority of transgender workers were having ages beyond forty years. There is a need of a drive to encourage young transgender people to obtain jobs and pursue a career path.

Transgender people represent a considerable part of the human population on earth and this human part is still not recognized as a resource and some of the researchers label it as invisible diversity. There is a need to put the transgender community into the mainstream of human resources. In this way, organizations can increase resource diversity and increase creativity and innovation opportunities. The consequences of disowning the transgender community are multiple. Organizations lose a valuable human resource and in return transgender community remains in poverty and the vicious circle continues.

\subsection{Recommendations}

Based on the findings of this study we extend the following recommendations:

- There is a need to recognize transgender people as a valuable human resource and to provide them with equal opportunities for employment, otherwise the loss is immense;

- Transgender people are equally competent and motivated. They possess all the cognitive and emotional capabilities that are required and appreciated at the workplace;

- Transgender people are equally responsible and any position corresponding to their abilities can be entrusted to them;

- It is a stereotypical error that transgender people are just entertainers and suitable for dance and sex work. This debilitating perception creates a barrier for the employability of transgender people;

- The Government of Pakistan should make policies to provide equal employment opportunities and equal human rights including education and health facilities to make visible this invisible diversity;

- Organizations should allocate quotas for transgender people to make sure they are represented in organizations. 


\subsection{Implications of the Study}

The findings of this study have both theoretical and managerial implications. The study has unearthed the fact that transgender people are an equally effective human resource; however, they are neglected. Their lifestyle, social configuration, and physical appearance and movements do not irritate coworkers. Transgender people need to improve their working capabilities by having the facilities to obtain a proper education, training, and health services. Researchers and academics should try to eliminate the devastating social perception that transgender people are substandard human beings and lack work competencies.

Managers can strengthen their human resources by the inclusion of transgender people in their workforce. The need is to own them, respect them, facilitate them, enable them, and provide work opportunities to them. Transgender people can approach work differently and enhance the possibility of innovation in processes or products. Managers can have cheap labor through the inclusion of transgender people. Managers should take corrective steps and break the stereotypical error that transgender people are inappropriate for jobs by involving more and more transgender people in their workforce.

This research has greater research implications and opens venues for further research in the area. Since the findings exhibit that qualified transgender people can obtain conducive work environment; however, certain factors such as isolation from family and other social circle, the deprivation of basic amenities such as education, health, insurance etc. create employment issues for transgender people. Further research is needed to understand the factual causes of social isolation and the deprivation of basic amenities of life and to explore the remedial measures to correct them.

Author Contributions: Conceptualization, Z.U. and N.A.; methodology, Z.U.; software, M.S. and R.T.N.; validation, N.A.; formal analysis, H.H. and R.T.N.; investigation, M.S.; writing-original draft preparation, Z.U.; writing—review and editing, E.A. and T.A.H.; supervision, H.H. All authors have read and agreed to the published version of the manuscript.

Funding: This research received no external funding.

Institutional Review Board Statement: Not required.

Informed Consent Statement: Informed consent was obtained from the respondents of the survey.

Data Availability Statement: The data will be made available on request from the corresponding author.

Conflicts of Interest: The authors declare no conflict of interest.

\section{References}

1. Grant, J.E.; Flynn, M.; Odlaug, B.L.; Schreiber, L.R. Personality disorders in gay, lesbian, bisexual, and transgender chemically dependent patients. Am. J. Addict. 2011, 20, 405-411. [CrossRef]

2. Peitzmeier, S.M.; Malik, M.; Kattari, S.K.; Marrow, E.; Stephenson, R.; Agénor, M.; Reisner, S.L. Intimate partner violence in transgender populations: Systematic review and meta-analysis of prevalence and correlates. Am. J. Public Health 2020, 110, e1-e14. [CrossRef] [PubMed]

3. Somasundaram, O. Transgenderism: Facts and fictions. Indian J. Psychiatry 2009, 51, 73. [CrossRef] [PubMed]

4. Mukhopadhyay, A.; Chowdhury, R. The eunuch patient. Trop. Dr. 2009, 39, 63-64. [CrossRef] [PubMed]

5. Siniscalco, G.R. Homosexual Discrimination in Employment. St. Clara L. Rev. 1975, 16, 495.

6. Benschop, Y.; Holgersson, C.; Van den Brink, M.; Wahl, A. Future Challenges for Practices of Diversity Management in Organizations. In Handbook for Diversity in Organizations; Oxford University Press: Oxford, UK, 2015; pp. 553-574.

7. Dietert, M.; Dentice, D. Gender identity issues and workplace discrimination: The transgender experience. J. Workplace Rights 2009, 14, 121-140. [CrossRef]

8. Ismail, M.A.; Shah, N.A. A Study On Psycho-Social; Physical Hazards And Society's Attitude Towards Eunuchs. Pak. J. Gend. Stud. 2018, 17, 55-78. [CrossRef]

9. David, E. Purple-collar labor: Transgender workers and queer value at global call centers in the Philippines. Gend. Soc. 2015, 29, 169-194. [CrossRef]

10. Chung, C.-S. Women's labor Force Participation through Work/Life Balance. Jpn. Spotlight 2010, 10, $26-27$.

11. David, E. Outsourced heroes and queer incorporations: Labor brokerage and the politics of inclusion in the Philippine call center industry. GLQ A J. Lesbian Gay Stud. 2016, 22, 381-408. [CrossRef] 
12. Becker, J. Transforming the Normative: Recognizing Diversity in Sex, Gender, and Sexuality; University of California: Davis, CA, USA, 2013

13. Sulcov, M.B. Transexualism: Its Social Reality; Indiana University: Bloomington, IN, USA, 1973.

14. Bockting, W.O.; Miner, M.H.; Swinburne Romine, R.E.; Dolezal, C.; Robinson, B.B.E.; Rosser, B.S.; Coleman, E. The Transgender Identity Survey: A measure of internalized transphobia. LGBT Health 2020, 7, 15-27. [CrossRef]

15. Hill, B.J.; Rosentel, K.; Bak, T.; Silverman, M.; Crosby, R.; Salazar, L.; Kipke, M. Exploring individual and structural factors associated with employment among young transgender women of color using a no-cost transgender legal resource center. Transgender Health 2017, 2, 29-34. [CrossRef]

16. Hotton, A.L.; Garofalo, R.; Kuhns, L.M.; Johnson, A.K. Substance use as a mediator of the relationship between life stress and sexual risk among young transgender women. AIDS Educ. Prev. 2013, 25, 62-71. [CrossRef]

17. Ringrose, K.M. The Perfect Servant: Eunuchs and the Social Construction of Gender in Byzantium; University of Chicago Press: Chicago, IL, USA, 2007.

18. Lerner, A.; He, H.Y.; Kawakami, A.; Zeamer, S.C.; Hoyle, R. Privacy and activism in the transgender community. In Proceedings of the 2020 CHI Conference on Human Factors in Computing Systems, Honolulu, HI, USA, 25-30 April 2020; pp. 1-13.

19. Taylor, G. Castration: An Abbreviated History of Western Manhood; Psychology Press: London, UK, 2002.

20. Tracy, L. Castration and Culture in the Middle Ages; DS Brewer: Cambridge, UK, 2013.

21. Walch, A.; Davidge-Pitts, C.; Safer, J.D.; Lopez, X.; Tangpricha, V.; Iwamoto, S.J. Proper care of transgender and gender diverse persons in the setting of proposed discrimination: A policy perspective. J. Clin. Endocrinol. Metab. 2021, 106, 305-308. [CrossRef] [PubMed]

22. Meer, T.; Lunau, M.; Oberth, G.; Daskilewicz, K.; Muller, A. Lesbian, Gay, Bisexual, Transgender and Intersex Human Rights in Southern Africa: A Contemporary Literature Review 2012-2016; HIVOS: Johannesburg, South Africa, 2017.

23. Dierckx, M.; Meier, P.; Motmans, J. "Beyond the box": A comprehensive study of sexist, homophobic, and transphobic attitudes among the Belgian population. Digest. J. Divers. Gend. Stud. 2017, 4, 5-34. [CrossRef]

24. Khan, S. What is in a name? Khwaja Sara, Hijra and Eunuchs in Pakistan. Indian J. Gend. Studies 2016, 23, 218-242. [CrossRef]

25. Reisner, S.L.; Poteat, T.; Keatley, J.; Cabral, M.; Mothopeng, T.; Dunham, E.; Holland, C.E.; Max, R.; Baral, S.D. Global health burden and needs of transgender populations: A review. Lancet 2016, 388, 412-436. [CrossRef]

26. Supateera, C.; Kleiner, B.H. Discrimination in government. Equal Oppor. Int. 1999, 18, 78-82. [CrossRef]

27. Axt, J.R.; Conway, M.A.; Westgate, E.C.; Buttrick, N.R. Implicit transgender attitudes independently predict beliefs about gender and transgender people. Personal. Soc. Psychol. Bull. 2021, 47, 257-274. [CrossRef]

28. Lombardi, E. Enhancing transgender health care. Am. J. Public Health 2001, 91, 869.

29. Kirk, J.; Belovics, R. Understanding and counseling transgender clients. J. Employ. Couns. 2008, 45, 29-43. [CrossRef]

30. Sausa, L.A. Updating college and university campus policies: Meeting the needs of trans students, staff, and faculty. J. Lesbian Stud. 2002, 6, 43-55. [CrossRef]

31. Souza, M.; Malvasi, P.; Signorelli, M.C.; Pereira, P. Violence and social distress among transgender persons in Santa Maria, Rio Grande do Sul State, Brazil. Cad. De Saude Publica 2015, 31, 767-776. [CrossRef] [PubMed]

32. Koch, K.; Bales, R. Transgender employment discrimination. UCLA Women's Law J. 2008, 17, 243.

33. Buss, J.; Le, H.; Haimson, O.L. Transgender identity management across social media platforms. Media Cult. Soc. 2021, 17, 1-17. [CrossRef]

34. Lee, J. Lost in Transition: The Challenges of Remedying Transgender Employment Discrimination Under Title VII. Harv. JL Gend. 2012, 35, 423.

35. McFadden, C. Hiring discrimination against transgender job applicants-considerations when designing a study. Int. J. Manpow. 2020, 41, 731-752. [CrossRef]

36. Waite, S. Should I stay or should I go? Employment discrimination and workplace harassment against transgender and other minority employees in Canada's federal public service. J. Homosex. 2020, 68, 1-27. [CrossRef] [PubMed]

37. Tanimoto, C.; Miwa, K. Factors influencing acceptance of transgender athletes. Sport Manag. Rev. 2021, $24,1-23$.

38. Eger, E.K. Transgender jobseekers navigating closeting communication. Manag. Commun. Q. 2018, 32, 276-281. [CrossRef]

39. Factor, R.J.; Rothblum, E.D. A study of transgender adults and their non-transgender siblings on demographic characteristics, social support, and experiences of violence. J. LGBT Health Res. 2007, 3, 11-30. [CrossRef]

40. Nascimento, F.K.; Reis, R.A.; Saadeh, A.; Demétrio, F.; Rodrigues, I.L.A.; Galera, S.A.F.; Santos, C.B.D. Brazilian transgender children and adolescents: Attributes associated with quality of life. Rev. Lat. Am. De Enferm. 2020, 28. [CrossRef] [PubMed]

41. Zimman, L. Transgender language reform: Some challenges and strategies for promoting trans-affirming, gender-inclusive language. J. Lang. Discrim. 2017, 1, 83-104. [CrossRef]

42. Bretherton, I.; Thrower, E.; Zwickl, S.; Wong, A.; Chetcuti, D.; Grossmann, M.; Zajac, J.D.; Cheung, A.S. The health and well-being of transgender Australians: A national community survey. LGBT Health 2021, 8, 42-49. [CrossRef] [PubMed]

43. Jones, B.A.; Pierre Bouman, W.; Haycraft, E.; Arcelus, J. Gender congruence and body satisfaction in nonbinary transgender people: A case control study. Int. J. Transgenderism 2019, 20, 263-274. [CrossRef]

44. Green, E.L.; Benner, K.; Pear, R. “Transgender" Could Be Defined Out of Existence Under Trump Administration. 2018. Available online: https:/ / www.nytimes.com/2018/10/21/us/politics/transgender-trump-administration-sex-definition.html (accessed on 20 July 2021). 
45. Sherman, A.D.; Allgood, S.; Alexander, K.A.; Klepper, M.; Balthazar, M.S.; Hill, M.; Cannon, C.M.; Dunn, D.; Poteat, T.; Campbell, J. Transgender and gender diverse community connection, help-seeking, and mental health among Black transgender women who have survived violence: A mixed-methods analysis. Violence Against Women 2021. [CrossRef]

46. Hardy, T.L.; Boliek, C.A.; Aalto, D.; Lewicke, J.; Wells, K.; Rieger, J.M. Contributions of voice and nonverbal communication to perceived masculinity-femininity for cisgender and transgender communicators. J. Speech Lang. Hear. Res. 2020, 63, 931-947. [CrossRef]

47. McCullough, R.; Dispenza, F.; Parker, L.K.; Viehl, C.J.; Chang, C.Y.; Murphy, T.M. The counseling experiences of transgender and gender nonconforming clients. J. Couns. Dev. 2017, 95, 423-434. [CrossRef]

48. McCann, E.; Brown, M.J. Homeless experiences and support needs of transgender people: A systematic review of the international evidence. J. Nurs. Manag. 2021, 29, 85-94. [CrossRef]

49. Riseman, N. Transgender Inclusion and Australia's Failed Sexuality Discrimination Bill. Aust. J. Politics Hist. 2019, 65, 259-277. [CrossRef]

50. Simon, D.; Read, S.J. Neither cognitive nor consistency: A comment on “Cognitive consistency theory in social psychology: A paradigm reconsidered". Psychol. Inq. 2018, 29, 97-108. [CrossRef]

51. Fiske, S.T. Stereotype content: Warmth and competence endure. Curr. Dir. Psychol. Sci. 2018, 27, 67-73. [CrossRef]

52. Gaspelin, N.; Luck, S.J. The role of inhibition in avoiding distraction by salient stimuli. Trends Cogn. Sci. 2018, 22, 79-92. [CrossRef]

53. Sharratt, N.D.; Jenkinson, E.; Moss, T.; Clarke, A.; Rumsey, N. Understandings and experiences of visible difference and romantic relationships: A qualitative exploration. Body Image 2018, 27, 32-42. [CrossRef] [PubMed]

54. Bradford, N.J.; Syed, M. Transnormativity and transgender identity development: A master narrative approach. Sex Roles 2019, 81, 306-325. [CrossRef]

55. Quintini, G. Right for the JOB: Over-Qualified or Under-Skilled? OECD Social, Employment and Migration Working Papers, No. 120; OECD: Tokyo, Japan, 2011.

56. Davies, G. Gender and Body Language in Roman Art; Cambridge University Press: Cambridge, UK, 2018.

57. Korzaan, M.L.; Boswell, K.T. The influence of personality traits and information privacy concerns on behavioral intentions. J. Comput. Inf. Syst. 2008, 48, 15-24.

58. Nooteboom, B. Trust: Forms, Foundations, Functions, Failures and Figures; Edward Elgar Publishing: Cheltenham, UK, 2002.

59. Islam, T.; Ahmed, I.; Ali, G. Effects of ethical leadership on bullying and voice behavior among nurses: Mediating role of organizational identification, poor working condition and workload. Leadersh. Health Serv. 2019, 32, 2-17. [CrossRef]

60. Leoni, R. Workplace design, complementarities among work practices, and the formation of key competencies: Evidence from Italian employees. ILR Rev. 2012, 65, 316-349. [CrossRef]

61. Maurer, T.J.; Weiss, E.M.; Barbeite, F.G. A model of involvement in work-related learning and development activity: The effects of individual, situational, motivational, and age variables. J. Appl. Psychol. 2003, 88, 707. [CrossRef] [PubMed]

62. Thomas, K.W. Intrinsic Motivation at Work: What Really Drives Employee Engagement; Berrett-Koehler Publishers: Oakland, CA, USA, 2009.

63. Henseler, J.; Hubona, G.; Ray, P.A. Using PLS path modeling in new technology research: Updated guidelines. Ind. Manag. Data Syst. 2016. [CrossRef]

64. Gefen, D.; Straub, D.; Boudreau, M.-C. Structural equation modeling and regression: Guidelines for research practice. Commun Assoc. Inf. Syst. 2000, 4, 7. [CrossRef]

65. Ab Hamid, M.; Sami, W.; Sidek, M.M. Discriminant validity assessment: Use of Fornell \& Larcker criterion versus HTMT criterion. In Journal of Physics: Conference Series; IOP Publishing: Bristol, UK, 2017; p. 012163.

66. Afthanorhan, W. A comparison of partial least square structural equation modeling (PLS-SEM) and covariance based structural equation modeling (CB-SEM) for confirmatory factor analysis. Int. J. Eng. Sci. Innov. Technol. 2013, 2, $198-205$.

67. Kock, N. Common method bias: A full collinearity assessment method for PLS-SEM. In Partial Least Squares Path Modeling; Springer: Berlin/Heidelberg, Germany, 2017; pp. 245-257.

68. Brewster, M.E.; Velez, B.; DeBlaere, C.; Moradi, B. Transgender individuals' workplace experiences: The applicability of sexual minority measures and models. J. Couns. Psychol. 2012, 59, 60. [CrossRef]

69. Russell, S.T.; Pollitt, A.M.; Li, G.; Grossman, A.H. Chosen name use is linked to reduced depressive symptoms, suicidal ideation, and suicidal behavior among transgender youth. J. Adolesc. Health 2018, 63, 503-505. [CrossRef] [PubMed]

70. Brewster, M.E.; Velez, B.L.; Mennicke, A.; Tebbe, E. Voices from beyond: A thematic content analysis of transgender employees' workplace experiences. Psychol. Sex. Orientat. Gend. Divers. 2014, 1, 159. [CrossRef]

71. Davis, D. Transgender issues in the workplace: HRD's newest challenge/opportunity. Adv. Dev. Hum. Resour. 2009, 11, 109-120. [CrossRef]

72. Kuefler, M. The Manly Eunuch: Masculinity, Gender Ambiguity, and Christian Ideology in Late Antiquity; University of Chicago Press: Chicago, IL, USA, 2001.

73. Nazir, N.; Yasir, A. Education, Employability and Shift of Occupation of Transgender in Pakistan: A Case Study of Khyber Pakhtunkhwa. Dialogue 2016, 11, 1-19.

74. Hughto, J.M.W.; Reisner, S.L.; Pachankis, J.E. Transgender stigma and health: A critical review of stigma determinants, mechanisms, and interventions. Soc. Sci. Med. 2015, 147, 222-231. [CrossRef]

75. Connell, R. Transgender health: On a world scale. Health Sociol. Rev. 2021, 30, 87-94. [CrossRef] 
76. Ganguly, J.; Mathur, K. Personality and social adjustment among transgender. Indian J. Health Wellbeing 2016, 7, 1131-1134.

77. Momen, R.E.; Dilks, L.M. Examining case outcomes in US transgender homicides: An exploratory investigation of the intersectionality of victim characteristics. Sociol. Spectr. 2021, 41, 53-79. [CrossRef] 